\title{
Predictors of difficulty in bedside percutaneous dilatational tracheostomy: pilot study
}

\section{Preditores de dificuldade em traqueostomia percutânea à beira do leito: estudo piloto}

Lucas Ribeiro Tenório ${ }^{1}$ (D); Marianne Yumi Nakai ${ }^{1,2}$; Júlio Patrocínio Moraes ${ }^{2}$; Marcelo Benedito Menezes, TCBC-SP1,2; Letícia de Melo Silva1; Guilherme Petry Martins Pereira ${ }^{1}$; Antonio José Gonçalves, TCBC-SP1,2.

\begin{abstract}
A B S T R A C T
Introduction: percutaneous dilatational tracheostomy is currently one of the main procedures performed in an intensive care unit (ICU). However, there are no well-defined indicators of technical difficulty in performing the procedure. Objectives: to define predictors of difficulty in performing bedside percutaneous dilatational tracheostomy. Methodology: prospective cohort study encompassing 21 patients who underwent bedside percutaneous dilatational tracheostomy in the ICU at a single center. Results: Sternohyoid (SH) distance shorter than $7 \mathrm{~cm}$ is associated with a $50 \%$ increase in the risk of technical difficulty (OR 0.44 and $p<0.03$ ). Conclusion: the reduction in (SH) distance is related to an increased risk of difficulty in performing percutaneous dilatational tracheostomy in the ICU bed.
\end{abstract}

Keywords: Tracheostomy. Airway Management. Intensive Care Units.

\section{INTRODUCTION}

$P$ ercutaneous dilatational tracheostomy (PDT) is now one of the main procedures performed in an intensive care unit (ICU). Technological evolution has been able to transform the tracheostomy, formerly feared and prohibited', into a procedure performed with a percutaneous technique outside the operating room environment. Despite being an elective procedure, with low complication rates ${ }^{2,3}$, the technique involves handling the airway of a critical patient, and failures in this management can be fatal ${ }^{4}$. However, there are no well-defined indicators of technical difficulty for the performance of PDT. Drawing a comparison with the procedure of orotracheal intubation and mainly with the predictors of difficulty to perform it, the lack of equivalent parameters when carrying out PDT is noteworthy.
Although the occurrence of complications related to PDT is uncommon ${ }^{4}$, significant adverse events are described, mainly related to injuries in structures adjacent to the trachea, such as the vascular network, with consequent hemorrhage or failure to insert the tracheal cannula ${ }^{5}$, with impaired patient ventilation. It is also worth remembering that, despite being a controlled environment, the intensive care unit is not routinely prepared for critical complications that may occur during surgical procedures ${ }^{5,7}$.

In the current literature, there is a great relativization of the contraindications for the percutaneous tracheostomy technique, and clinical practice is directed to the individualization of cases. Several factors, mainly anatomical, can cause difficulties, such as kyphosis, scoliosis, tracheomalacia, tracheal calcification, anatomical variations, airway deviations for various reasons, obesity, among others ${ }^{4,8}$. Based

1 - Santa Casa de São Paulo School of Medical Science, Discipline of Head and Neck Surgery - São Paulo - SP - Brazil 2 - Irmandade da Santa Casa de Misericórdia de São Paulo, Department of Surgery / Head and Neck Surgery Discipline - São Paulo - SP - Brazil 
on this premise, we propose to analyze the patients' intrinsic factors that may cause difficulties in performing PDT. With established predictors, it will be possible to avoid catastrophic procedures in the ICU and redirect these patients to the operating room, with structured apparatus to perform the procedure, usually using the conventional open surgical technique.

\section{GOALS}

To define predictors of difficulty in performing percutaneous dilatational tracheostomy.

\section{METHODS}

This is an observational prospective cohort study, in which we included 21 patients who underwent bedside percutaneous dilatational tracheostomy in the ICU at a single center.

A trained head and neck surgeon, with experience in PDT, performed the procedure. In all cases, the tracheostomy was guided by bronchoscopy (performed by a bronchoscopist or another head and neck surgeon trained in bronchoscopy). All procedures were performed in the ICU bed.

We collected data on age, sex, obesity, time of orotracheal intubation, size of the orotracheal cannula, sternohyoid (SH) distance, sterno-cricoid (SC) distance, presence of calcified trachea, tracheomalacia, thyroid goiter, and palpable trachea (Table 1).

The head and neck surgeon determined the presence of obesity, thyroid goiter, tracheomalacia and calcified trachea by clinical evaluation.

We measured the sternohyoid ( $\mathrm{SH}$ ) and sternocricoid (SC) distances with a flexible ruler, in a straight line, with the patient in horizontal supine position, in cervical hyperextension (Figure 1) (Figure 2).

We considered a difficult procedure the one displaying at least one of the following items: prolonged time; more than one tracheal puncture; dilation difficulty; and difficulty of the procedure referred by the surgeon.

We collected data on complications related to the procedure until the seventh postoperative day.

We used the REDCap software for the collection and management of clinical data.

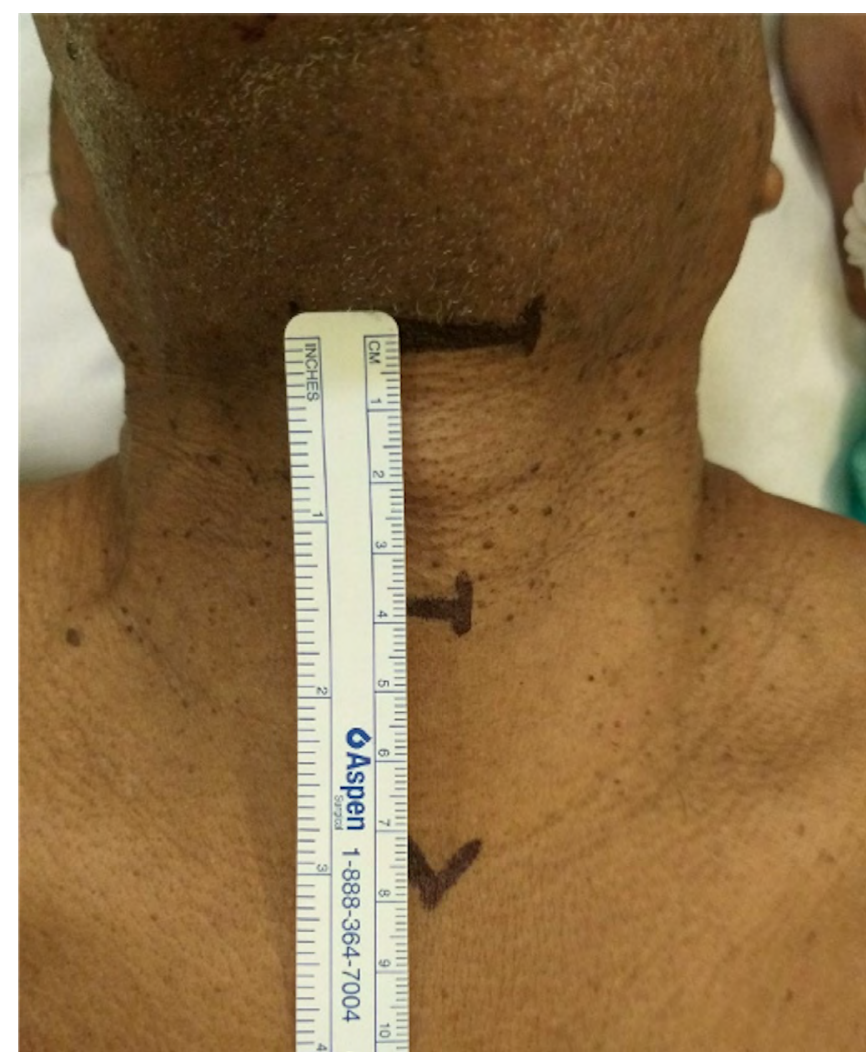

Figure 1. Distance measured with a flexible tape between the sternohyod and the sterno-cricoid.

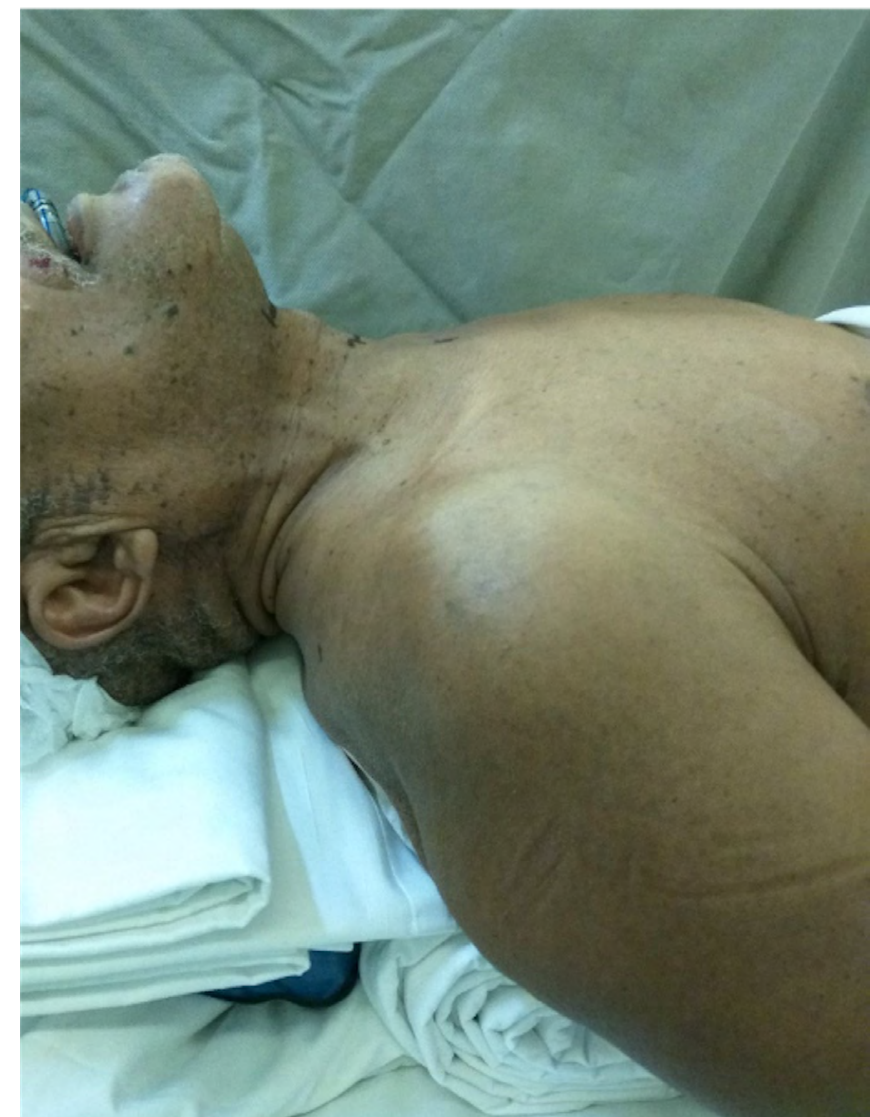

Figure 2. Patient positioning in hyperextension before the measurement of the sternohyod and the sterno-cricoid distances. 
Table 1. Characteristics of the sample.

\begin{tabular}{|c|c|c|c|c|c|c|c|c|c|c|c|c|c|c|}
\hline$\#$ & Sex & $\begin{array}{c}\mathrm{SH} \\
(\mathrm{cm})^{*}\end{array}$ & $\begin{array}{c}\mathrm{SD} \\
(\mathrm{cm})^{*}\end{array}$ & $\begin{array}{l}\text { Palpable } \\
\text { trachea }\end{array}$ & $\begin{array}{l}\text { Calcified } \\
\text { trachea }\end{array}$ & Malacia* & Goit & Obesity & $\begin{array}{c}\text { OTI } \\
\text { (days) }\end{array}$ & $\begin{array}{c}\mathrm{N} \\
\text { tube* }\end{array}$ & $\begin{array}{c}\mathrm{N} \\
\text { Punctures* }\end{array}$ & $\begin{array}{c}\text { Dilation } \\
\text { difficulty* }\end{array}$ & $\begin{array}{c}\text { Passage } \\
\text { diffifculty* }\end{array}$ & Difficulty* \\
\hline 1 & $M$ & 11 & 5 & $\begin{array}{c}\text { With } \\
\text { extension }\end{array}$ & No & No & No & No & 12 & 8.5 & 1 & No & No & No \\
\hline 2 & $\mathrm{~F}$ & 10 & 4 & Yes & No & No & No & No & 20 & 7 & 1 & No & No & No \\
\hline 3 & $M$ & 11 & 4 & Yes & No & No & No & No & 18 & 8 & 1 & No & No & No \\
\hline 4 & $F$ & 7 & 4 & Yes & No & No & No & No & 19 & 7 & 1 & No & No & No \\
\hline 5 & $M$ & 12 & 6 & $\begin{array}{l}\text { With } \\
\text { extension }\end{array}$ & No & No & No & No & 9 & 8 & 1 & No & No & No \\
\hline 6 & $\mathrm{~F}$ & 6 & 4 & $\begin{array}{c}\text { With } \\
\text { extension }\end{array}$ & No & No & No & No & 11 & 7.5 & 1 & No & No & No \\
\hline 7 & $M$ & 13 & 7 & Yes & No & No & No & No & 13 & 8 & 1 & No & No & No \\
\hline 8 & M & 13.5 & 8 & Yes & No & No & No & No & 44 & 8 & 1 & No & No & No \\
\hline 9 & M & 10 & 5.5 & Yes & No & No & No & No & 9 & 8 & 1 & No & No & No \\
\hline 10 & M & 10 & 3 & Yes & No & No & No & No & 12 & 8.5 & 1 & No & No & No \\
\hline 11 & $\mathrm{M}$ & 11 & 4 & Yes & No & No & No & No & 9 & 8 & 1 & No & No & No \\
\hline 12 & $M$ & 9 & 3 & Yes & No & No & No & No & 7 & 7.5 & 1 & No & No & No \\
\hline 13 & $M$ & 10 & 5 & Yes & No & No & No & No & 19 & 7.5 & 1 & No & No & No \\
\hline 14 & $M$ & 12 & 4 & Yes & No & No & No & No & 9 & 7.5 & 1 & No & No & No \\
\hline 15 & $\mathrm{M}$ & 10 & 5.5 & Yes & No & No & No & No & 12 & 8 & 1 & No & No & No \\
\hline 16 & $M$ & 8 & 3 & Yes & No & No & No & No & 13 & 8 & 1 & No & No & No \\
\hline 17 & $\mathrm{~F}$ & 5 & 2 & $\begin{array}{c}\text { With } \\
\text { extension }\end{array}$ & No & No & No & & 9 & 7.5 & 1 & No & No & Yes \\
\hline 18 & $M$ & 6 & 2 & $\begin{array}{l}\text { With } \\
\text { extension }\end{array}$ & No & No & No & No & 12 & 8 & 2 & No & No & Yes \\
\hline 19 & $M$ & 8 & 4 & Yes & No & No & No & No & 15 & 8 & 2 & No & No & Yes \\
\hline 20 & $M$ & 7 & 2 & $\begin{array}{l}\text { With } \\
\text { extension }\end{array}$ & No & No & No & No & 10 & 8 & 1 & No & No & Yes \\
\hline 21 & $\mathrm{~F}$ & 11 & 6 & Yes & No & No & Yes & Yes & 23 & 8 & 2 & No & No & Yes \\
\hline
\end{tabular}

*Legend

$\mathrm{SH}=$ sternohyod distance in centimeters; $S D=$ Sternocricoid distance; Malacia = presence of tracheomalacia; OTI = orotracheal intubation; $\mathrm{N}$ tube = number of the orotracheal tube; $N$ punctures = number of tracheal punctures; Dilation difficulty = difficult tracheal dilation; Passage difficulty = difficult placement of the tracheostomy tube; Difficulty - it was considered a difficult procedure when there was at leas one of the following conditions: long surgical time; more than one tracheal puncture; difficult dilation or reported difficult procedure by the surgeon.

\section{Statistical analysis}

We entered the data into the Stata IC v16 for Mac software.

We performed univariate analysis by logistic regression of all variables collected, to verify association with the outcome. The variables with $p<0.20$ were selected for multivariate analysis ${ }^{9}$.

We then performed a multivariate analysis by logistic regression, and chose the best model using the technique described by Hosmer and Lemeshow Purposeful selection of covariates $^{10}$.

We considered associations with $p<0.05$ as statistically significant ${ }^{9}$.

\section{RESULTS}

We included 21 patients, with a mean age of 60 years, 16 (76\%) of whom were male, and 5 (24\%), female. The mean time of orotracheal intubation was 14 
days (Table 1).

During follow-up, only two patients displayed complications in the first seven days, both having postoperative bleeding without clinical repercussion and without the need for surgical re-approach, resolved with a compressive dressing. There were no reports of other complications.

Age, sex, time of orotracheal intubation, obesity, thyroid goiter, tracheomalacia and calcified trachea did not present a statistically significant association with the difficulty of the procedure, either by univariate or by multivariate analysis.

The SH distance had no statistically significant association by univariate analysis. However, in the multivariate analysis it was a predictor of reduction in difficulty, and $\mathrm{SH}$ distance shorter than $7 \mathrm{~cm}$ increased the probability of difficulty by $50 \%(O R \quad 0.44, p<0.03$ ) (Graphic 1).

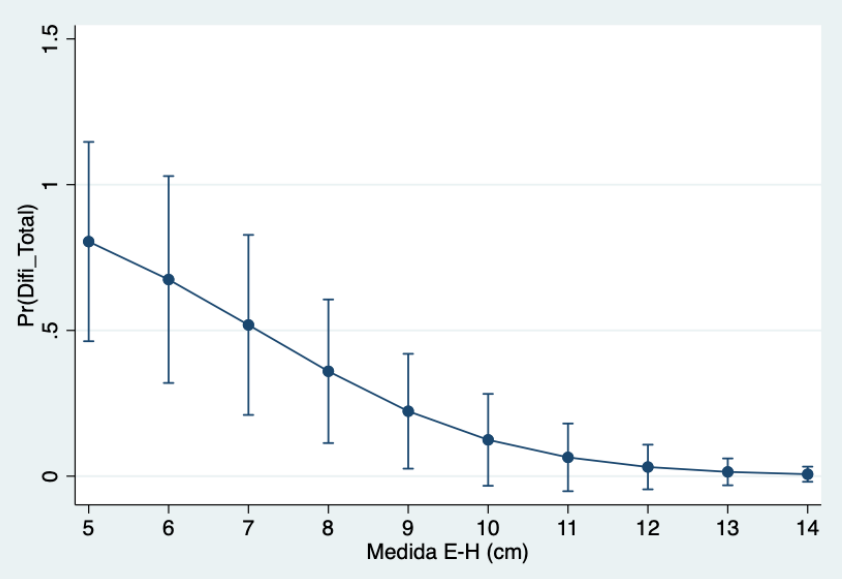

Graph 1. Probability of having difficulty to carry out the procedure regarding the sternohyod distance ( $O R=0.44 p=0.03$ ).

*The graphic was created by the Stata IC V16 software for Mac, after a multivariate logistic re-gression analysis showing the respective confidence intervals (Cl-95\%) ** Outcome (y axis) - probability of difficulty to carry out the procedure/predictor ( $\mathrm{x}$ axis) - sternohyod distance $(\mathrm{cm})$ measured as straight line, having the patient in cervical extension $* * *$ The difficulty was defined as the presence of at least one of the following items: long time to carry it out; more than one tracheal puncture; difficult dilation; and surgeons' report of having had difficulty ot carry out the procedure.

\section{DISCUSSION}

In our study, SH distance was a predictor of difficulty in performing percutaneous dilatational tracheostomy. SH Distance less than $7 \mathrm{~cm}$ was associated with a $50 \%$ increase in the chance of technical difficulty (OR 0.44, p<0.03).

The other variables displayed no significant association. However, due to the reduced sample size, it is not possible to exclude them as predictors. We believe that SC distance is also an important predictor and we are expanding the study to include more patients and other centers. Another limitation was the subjective analysis of some variables based on the surgeon's assessment (obesity, goiter, tracheomalacia and calcified trachea). Despite being subjective, these variables were determined by a specialist in head and neck surgery and were chosen to increase the feasibility of the study, since the patients were clinically severe and, ideally, diagnostic procedures should not be added.

Current literature on the subject is scarce. There are no predictors of difficulty in PDT and the contraindications for it vary between different authors $3,8,11,12$. Tracheostomy is a routine procedure in intensive care units and its performance has been increasing over the last decades in parallel with the increased use of mechanical ventilation and the longer survival of critically ill patients $2,11,13$.

Despite the low rate of complications associated with the method ${ }^{11}$, complications during the performance of the tracheostomy can cause death. The complications most frequently associated with the procedure are hemorrhages and failure to insert the tracheostomy cannula .

Finding predictors for percutaneous tracheostomy is essential to minimize fatal risks. Patients with an SH distance of less than $7 \mathrm{~cm}$ are at increased risk for difficulty and, therefore, the attending team should consider preparing for the eventual conversion to open surgery. In addition, all tracheostomies performed in this study were guided by bronchoscopy, and for this reason, we consider it appropriate to use a method to guide the procedure (ultrasound or bronchoscopy), especially for patients with reduced SH distance.

\section{CONCLUSION}

Short SH distance is related to an increased risk of difficulty in performing bedside percutaneous dilatational tracheostomy at the ICU. 


\section{R E S U M O}

Introdução: a traqueostomia percutânea é hoje um dos principais procedimentos realizados em unidade de terapia intensiva (UTI). Não há, contudo, indicadores bem definidos de dificuldade técnica na realização do procedimento. Objetivos: definir preditores de dificuldade para realização de traqueostomia percutânea. Metodologia: estudo de coorte prospectivo no qual foram incluídos 21 pacientes submetidos a traqueostomia percutânea à beira do leito, na UTI, em um único centro. Resultados: distância EH menor que $7 \mathrm{~cm}$ está associada a aumento de $50 \%$ na chance de dificuldade técnica $(O R$ 0,44 e p<0,03). Conclusão: a redução da distância EH está relacionada com aumento do risco de dificuldade em realizar a traqueostomia percutânea à beira do leito, em UTI.

Palavras chave: Traqueostomia. Manuseio das Vias Aéreas. Unidades de Terapia Intensiva.

\section{REFERENCES}

1. Szmuk P, Ezri T, Evron S, Roth Y, Katz J. A brief history of tracheostomy and tracheal intubation, from the Bronze Age to the Space Age. Intensive Care Med. 2008;34(2):222-8.

2. Perfeito JAJ, Da Mata CAS, Forte $V$, Carnaghi M, Tamura N, Leão LEV. Traqueostomia na UTI: vale a pena realizá-la? J Bras Pneumol. 2007;33(6):687-90.

3. Johnson-Obaseki $S$, Veljkovic $A$, Javidnia $H$. Complication rates of open surgical versus percutaneous tracheostomy in critically ill patients. Laryngoscope. 2016;126(11):2459-67.

4. Nakai MY, Benedito M, Kavabata NK, Suehara $A B$, Bertelli AAT, Kikuchi $W$, et al. Percutaneous Tracheostomy: Pearls and Pitfalls, and How to Create a "Hand-On" Training Program Course. In: de Farias TP, editor. Tracheostomy: A Surgical Guide. Cham(SWI): Springer International Publishing; 2018. p. 93-117.

5. Terra RM, Fernandez A, Bammann RH. Bedside tracheostomy: practical considerations. J Bras Pneumol. 2008;34(2):126.

6. Ikeda Y, Takami H, Niimi M, Kan S, Sasaki Y, Takayama J. Endoscopic thyroidectomy by the axillary approach. Surg Endosc. 2001;15(11):1362-4.

Received in: 23/02/2020

Accepted for publication: 01/04/2020

Conflict of interest: no.

Funding source: none.
7. Urban $C$ de A, Dellê LAB, Sluminsky BG, Hahn CG, Takizawa N, Yuasa LD. Traqueostomia a beira de leito na uti: estudo prospectivo de 70 casos. Rev Col Bras Cir. 1999;26(2):103-7.

8. Araujo GA, Bertelli AAT, Urbano $H$ de $R$, Nakai MY, Namur CS, Menezes MB, et al. Bedside conventional tracheostomy. Arch Head Neck Surg. 2018;47(1):e0873.

9. Rosner B. Fundamentals of Biostatistic. 7th ed. Boston (MA): Brooks/Cole; 2011.

10. Bursac Z, Gauss CH, Williams DK, Hosmer DW. Purposeful selection of variables in logistic regression. Source Code Biol Med. 2008;3(1):17.

11. Brass P, Hellmich M, Ladra A, Ladra J, Wrzosek A. Percutaneous techniques versus surgical techniques for tracheostomy. Cochrane Database Syst Rev. 2016;7(7):CD008045.

12. Klotz R, Klaiber U, Grummich K, Probst P, Diener $M K$, Büchler MW, et al. Percutaneous versus surgical strategy for tracheostomy: protocol for a systematic review and meta-analysis of perioperative and postoperative complications. Syst Rev. 2015;4(1):105.

13. Yang A, Gray ML, McKee S, Kidwai SM, Doucette J, Sobotka S, et al. Percutaneous versus surgical tracheostomy: timing, outcomes, and charges. Laryngoscope. 2018;128(12):2844-51.

\section{Mailing address:}

Lucas Ribeiro Tenório

E-mail: tenoriolr@gmail.com 